
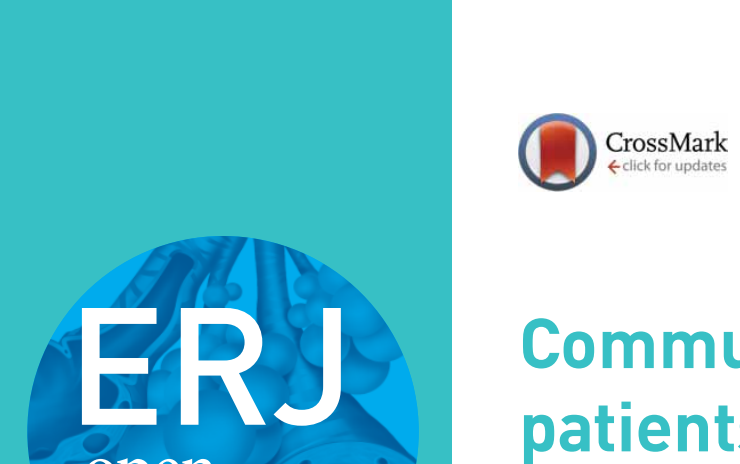

\title{
Communication difficulties reported by patients diagnosed with idiopathic pulmonary fibrosis and their carers: a European focus group study
}

\author{
Sarah Masefield ${ }^{1}$, Nicola Cassidy ${ }^{2}$, Derek Ross ${ }^{\dagger}$, Pippa Powell $^{1}$ and Athol Wells ${ }^{3}$ \\ Affiliations: ${ }^{1}$ European Lung Foundation, Sheffield, UK. ${ }^{2}$ Irish Lung Fibrosis Association, Dublin, Ireland. \\ ${ }^{3}$ Royal Brompton and Harefield Hospital, London, UK.
}

Correspondence: Pippa Powell, European Lung Foundation, 442 Glossop Road, Sheffield, UK. E-mail: pippa.powelldeuropeanlung.org

ABSTRACT This paper explores commonalities in the experience and unmet needs of idiopathic pulmonary fibrosis (IPF) patients and carers in Europe throughout the care pathway, focusing specifically on the unmet communication needs of patients and carers.

Four patient organisations/groups in Europe held focus groups (Italy (seven patients and four carers); Belgium (six patients); Ireland (23 patients and 10 carers); and England, UK (five patients and three carers)). A focus group schedule was provided and translated into the language of each focus group by the European Lung Foundation (ELF). Content analysis was conducted by the ELF and verified by the authors of the paper.

Three main themes emerged: professional-patient, professional-professional and patient-patient communication. Within these themes, eight priority areas were highlighted by two or more of the focus groups. In addition, 17 suggested action points were identified.

Patients and carers in Europe have unmet communication needs, which could be met by specialist physicians and specialist centres providing more effective information and signposting to support services, including support groups and patient organisations.

@ERSpublications

People with IPF and their carers reported communication challenges with healthcare professionals, between healthcare professionals and from patient to patient, during four focus groups held in different countries in Europe http://bit.ly/2LaJXQF

Cite this article as: Masefield S, Cassidy N, Ross D, et al. Communication difficulties reported by patients diagnosed with idiopathic pulmonary fibrosis and their carers: a European focus group study. ERJ Open Res 2019; 5: 00055-2019 [https://doi.org/10.1183/23120541.00055-2019].

Received: Feb 272019 | Accepted after revision: April 092019

Copyright $\odot E R S$ 2019. This article is open access and distributed under the terms of the Creative Commons Attribution Non-Commercial Licence 4.0. 


\section{Introduction}

Idiopathic pulmonary fibrosis (IPF) is a chronic, progressive and debilitating interstitial lung disease (ILD), with a median untreated survival of $2-5$ years from diagnosis. The major impact of IPF on quality of life for patients and families is increasingly recognised, with the need for high-quality information, support and appropriate therapies $[1,2]$.

Patient-centred care, with informed patients as active partners in their treatment, is grounded on effective communication between the patient, their physician, and other healthcare professionals and support services [3, 4]. Clear, effective and positive communication between the physician and the patient improves outcomes in patient satisfaction, engagement, compliance and self-management [4]. Few studies in IPF have focused on communication between patients and healthcare professionals across the care pathway (from receiving a diagnosis to discussions of end-of-life care) and its impact on the patient experience $[5,6]$. The goals of this qualitative study were to identify the communication challenges reported by patients and carers across Europe, and elicit ideas for improvement.

\section{Methods}

In 2013, the European Lung Foundation (ELF) (www.europeanlung.org) established a working group on patient-centred issues for people with IPF comprised of six healthcare professionals from the European Respiratory Society, an IPF patient, a family carer who also represented the Irish Lung Fibrosis Association (ILFA) and an ELF coordinator. The working group identified seven topics for patient and carer consultation, which are listed in the first column of table 1.

Focus group discussions were considered the optimal way to obtain direct input from a variety of patients and carers on their real-life experiences of these topics. Using a focus group approach was also the most efficient way to elicit input from patients and carers in different European countries. ELF invited eight European patient organisations to hold focus groups to discuss the topics proposed by the working group with their patient and carer members. Four organisations participated: AMA Fuori dal buio, Italy; Belgische Vereniging voor Longfibrose (BVL), Belgium; ILFA; and the Bristol Pulmonary Fibrosis Support Group, England, UK.

All focus group participants were provided with information in advance and gave informed consent to participate. An ILD nurse was present at each focus group, except those in Ireland. A psychologist was also present at the group in England. ELF produced a systematic guide for focus group leaders and note-takers to ensure that each group covered the topics in a structured way, using the same schedule and timings. The guide was produced in English and professionally translated into the other languages of the participating organisations.

The note-taker in each focus group recorded the discussion and produced a report, which was translated into English where necessary. Report-writing guidance was provided to enable comparison between reports. The reports indicated the points on which participants reached consensus and also those points in which there were differences of opinion or experience (e.g. "all participants agreed", "the majority of participants agreed" or "two or more people's opinions differed"). The reports were analysed individually and collectively, using content analysis. Analysis of emergent themes highlighted key patient priorities for patients and carers in different countries. The analysis was reviewed and independently verified by S. Masefield, N. Cassidy and A. Wells. Themes raised by fewer than two groups were discounted. Different numbers of patients and carers participated in the different focus groups, but the content analysis gave equal weighting to contributions made by each group.

\section{TABLE 1 Topics identified for patient and carer consultation}

\section{By the working group}

Definitions of mild, moderate and severe IPF Communication of diagnosis

Misdiagnosis and incorrect treatment

Medication issues

Patient-centred outcomes

Ongoing care and advanced care

New research on diagnosis and treatment

\section{By the focus groups}

Lung transplantation

Financial impact of IPF

Reliable information and doctor-patient communication Maximising quality of life

Patient and family support

Exercise and pulmonary rehabilitation

IPF: idiopathic pulmonary fibrosis. 
A further six items were identified by the focus groups and are listed in the second column of table 1.

\section{Results}

Four national patient organisations held a total of eight focus groups between July 2013 and March 2015, and submitted a report to ELF. 58 people participated in the focus groups across Europe: five patients and three carers in England; seven patients and four carers in Italy (two focus groups); six patients in Belgium; and 23 patients and 10 carers in Ireland (five focus groups).

The communication issues highlighted by the focus group participants were categorised into three main themes with several priority areas (table 2).

The patients' and carers' experiences are summarised and, where appropriate, described in their own words. Suggestions for ways to improve communication, build better relationships and enhance the healthcare experience are also presented.

\section{Professional-patient}

Effective and empathic communication

For effective communication with their physicians, patients and carers wanted plain language, honesty and empathy. They identified the importance of having adequate time available to ask their doctors questions, especially at the point of diagnosis: "Doctors should be sensitive when delivering a diagnosis and prognosis to patients. The delivery of a diagnosis should not be rushed as the news is life changing. Time should not be an issue." Ideally, patients would like a follow-up appointment 1-4 weeks after the diagnosis, giving them time to overcome the shock of the diagnosis so that at the follow-up appointment they are able to concentrate on their medical information needs relating to treatment and management.

Patients wanted information about their diagnosis and test results directly from an ILD specialist who could explain what the diagnosis meant in terms they could understand. Many patients did not comprehend the terminology of the staging of their lung disease, and how descriptions of "mild", "moderate" or "severe" related to their current health status, predicted life span and quality of life: "If somebody says to you it's mild, moderate or severe, all that immediately goes through your mind is does that mean I have a short life or a long one? It doesn't tell you what you're faced with.” Patients placed value on knowing their spirometry and 6-min walk test results, and comparing these with previous results, but wanted to know how this related to their condition in terms of their ability to perform daily activities, levels of fatigue and breathlessness.

Patients valued a balance of honesty and hope. They wanted the physicians to be realistic about the diagnosis and communicate the uncertainties of the progression of IPF, but without being too negative: "The diagnosis was communicated to me in a realistic manner. 'There is no treatment and no cure but' I remember the doctor emphasised that but - 'but there is a medicine that gives encouraging results'." They also felt that the clinician should recognise the patient's fears.

Patients stated that the key messages to communicate at the point of diagnosis are: 1) what IPF is, 2) that there is no cure, and 3) that IPF is chronic and progressive, but 4) that there are effective treatments to slow progression and manage symptoms.

The patients wanted to be able to access as much or as little information as they needed and the view did vary across the focus groups, with some patients wanting to know all they could about their condition (including how it developed, why it might have developed, the stages of it, prognosis, therapy options, etc.), whilst other patients just want to know that they have it. This led to the patients' perspective that layered information sources are needed so that those that want the basics can find them easily and those that want more can drill down to find it when they want to. It is important to note that these information

TABLE 2 Main themes and priority areas highlighted by the idiopathic pulmonary fibrosis focus group participants

\begin{tabular}{|c|c|c|}
\hline Professional-patient & Professional-professional & Patient-patient \\
\hline $\begin{array}{l}\text { Effective and empathic } \\
\text { communication }\end{array}$ & $\begin{array}{l}\text { Specialist physician to other healthcare } \\
\text { professionals }\end{array}$ & $\begin{array}{l}\text { Support groups and patient } \\
\text { organisations }\end{array}$ \\
\hline $\begin{array}{l}\text { Point of contact } \\
\text { Medication guidance } \\
\text { Advanced care planning }\end{array}$ & $\begin{array}{l}\text { Referral to rehabilitation and support } \\
\text { services }\end{array}$ & Carer and family support \\
\hline
\end{tabular}


needs may change as patients come to terms with the diagnosis and their condition advances. Many focus group participants considered the specialist physician and centre their primary source of information. The patients often wanted their partner/family involved in the treatment decision-making, but noted that the carer's information needs may vary from the patient's and should be managed sensitively by the physician.

The focus group participants wanted to know and understand the treatment options to enable them to make informed decisions. Some patients wanted to understand why certain options were not available to them (e.g. lung transplantation). Understanding the options could help patients come to terms with their diagnosis and provide hope: "Being told you have this and there is nothing you can do is frightening. I was told that I wasn't suitable for transplant so I felt in a position of no hope. I just had to sit down and take what was coming with no hope, and that was the worst of all."

The focus group members also wondered if guidance could help patients and carers to communicate more effectively with their physicians. The patients suggested that if they knew the information and detail that was required for their review appointments, they could keep a health diary and report changes that could be important indicators of disease progression or non-IPF pathology. The patients questioned if being more communicative about their health status could have accelerated their diagnosis. For example, one patient felt that they should have "taken a more proactive approach and taken personal responsibility for getting a diagnosis".

Point of contact

Each focus group stated the importance of having a point of contact or "helpline" that they could contact by telephone, e-mail or in person outside of their scheduled clinical appointments; for example, a healthcare professional with specialist knowledge of IPF, such as an ILD nurse. The ILD nurse could also meet the patient's need to see a specialist 1-4 weeks after their initial diagnosis: "I know I can always phone my ILD Nurse Specialist and talk to her. She is a fountain of knowledge about it all. When I come for my appointment, she always spends time going through everything; that's really vital." The patients found it reassuring to have a nurse who they could contact if they thought their symptoms had changed, and could spend time explaining their results and listening to their concerns.

This point of contact could also meet the patients' ongoing information needs by providing clear and concise printed information and alerting them to plain language resources online. Each focus group raised concerns about the quality and reliability of information via the Internet, which could sometimes be alarming to read. They suggested that specialist centres provide a list of sites that provide accurate and reliable information, and warn the patient about websites that provide incorrect information. The point of contact should also be able to facilitate practical support (e.g. disability and welfare benefits, and ongoing research studies) if they are interested.

\section{Medication guidance}

Many patients felt they took too many tablets, and sought explanations and reassurances from their physician, as well as information on the medication's side-effects and strategies to manage them. They wanted someone they could go to when they have concerns about drug interactions: "I am certain there is an interaction going on between some of the tablets but I don't know who to talk to. You feel like you have no-one in control of it." The patients reported reading the drug information leaflets but finding them frightening or inaccessible due to the medical language.

Medications prescribed by different specialists for comorbidities also caused anxiety. The patients wanted reassurance that different specialists were communicating with each other in order to reach agreement on drug regimens. The patients lacked confidence in local nonspecialised doctors, who they felt had inadequate knowledge of IPF. This is being and can be improved further with the shared-care model, where local physicians can specialise in conditions such as ILD.

\section{Advanced care planning}

There was some discomfort within the focus groups with discussions about advanced care planning/ end-of-life care because some individuals preferred to focus on the present and not the future. Some individuals had attempted to raise the subject with their partner or families but were prevented: "I have tried to talk about this with my wife, but she interrupted me suddenly; she does not even want to hear me talk."

A number of patients found it hard to consider advanced care planning until it became a necessity. However, they did agree that it would be important to have prompt access to a team who would be able to support them in the community as their condition changes and they become less well. Although some of the focus group patients were uncomfortable discussing the topic in a peer group setting, they felt there 
was a need for their doctor to speak with them one-to-one, sensitively, to engage in the discussion when they raised it or when the physician identified a medical imperative.

\section{Professional-professional}

\section{ILD physician to other healthcare professionals}

People with IPF are often reviewed by several doctors, including their specialist ILD physician, other doctors within the ILD centre, respiratory and/or nonrespiratory specialists for comorbidities, and their local doctor. Patients raised concerns that poor interprofessional communication could negatively impact their health; for example, patients questioned the quality of the care they received when admitted to hospital and treated by a doctor with no experience of IPF: "I now have a heart problem as well as my lungs. I got very upset about all this because nobody seemed to understand the conditions that I have. I was in [hospital] for my heart, therefore nothing else mattered." The patients also perceived inadequate communication when asked to explain their condition time and time again to healthcare professionals. They felt that maintaining and consulting concise, comprehensive patient medical records should reduce this need.

The patients wanted specialist physicians always to communicate their diagnosis to their local doctor with details about their treatment. The patients want to continue seeing their local doctor for IPF symptoms and non-IPF health concerns but reported feeling vulnerable and lacking confidence in healthcare professionals who were perceived to have little understanding of IPF: "I don't think there is any point in ringing my surgery now. My new doctor is OK but I don't think she knows about my lungs." The patients felt that local and other primary care doctors would benefit from guidance from specialists.

\section{Referral to rehabilitation and support services}

Participants of the focus groups wanted referrals for early rehabilitation and quality of life services to be available when they begin to lose physical independence or experience psychological challenges (such as at diagnosis or the advanced planning stage). Nutrition and smoking cessation services could also be valuable for some patients. They felt it was the physician's responsibility to be aware of local services, and communicate the importance of maintaining activity tolerance and support for psychological wellbeing: "I think the best advice I was given was by an ILD consultant and nurse. 'Do as much as you can."'; "Patients should be encouraged to stay as active as they can and as motivated as possible." One patient described how following her diagnosis and lack of information about staying active, her confidence was severely affected, resulting in her becoming housebound. The physician should also stress the relationship between physical activity and respiratory function for people being considered for lung transplantation, and to people for whom pulmonary rehabilitation referral is not suitable, they should explain the reasons. Social contact during rehabilitation was as important for most people as the physical activity component.

The psychological impact of IPF was stressed throughout. Anxiety and depression are common, with anxiety most acute at the stages of diagnosis and disease progression. The patients who had received counselling found that any scepticism about seeing a psychologist quickly disappeared after the first contact. All patients agreed that emotional health should be a priority as well as physical health, and that referral to a specialist psychologist with some knowledge of IPF can be exceptionally useful to help patients get through the times when they feel down.

\section{Patient-patient}

Support groups and patient organisations

The focus group members were all involved with local support groups (Bristol support group) or national patient organisations (ILFA, AMA Fuori dal buio and BVL), and were very positive about their role in providing information and support to patients, carers and families. They noted initial anxieties around meeting other patients and the encouragement provided by partners before they realised the value of getting involved: “I didn't feel I wanted to go because I thought it would be all older people, but when I went I listened to all the speakers, everything was really helpful for me. I am really thankful. I said I am going back again; it is a lot of help."

The peer interaction at support groups provided positive benefits and learning opportunities for adapting to life with IPF: "Patients will regularly talk to one another about their medication and give each other tips." Being able to talk face to face with other IPF patients helped them maintain a positive approach and speaking with people who are at different stages of disease progression also had benefits: "People are ultimately surprised by the opportunities still open to them and they realise, after talking to others in the same position, that each case is different."

Peer support was especially helpful for addressing anxieties around oxygen and lung transplantation. For lung transplantation, is it useful to have the opportunity to meet others who have had a transplant both 
before and after the surgery to give hope and positive reinforcement that it is/was the right decision: "Patients who are on the waiting list for a transplant gain courage from being around those who have already had the operation. They can form a better picture as a result of contact with people who have had a transplant."

The patients felt that physicians and specialist centres should routinely inform patients about local support groups and/or national organisations, clearly stating the information and support that they can offer and the value that others have found in connecting with these groups. Information about patient organisations should be displayed in ILD centres as well as printed information provided at diagnosis. This signposting role is important because most of the focus group members were not aware of IPF before their diagnosis.

\section{Carer and family support}

The impact of IPF on the patient's partner and family was raised by each focus group because the "partners of people with lung fibrosis suffer with them". Having a close relationship with someone with IPF was described as a "heavy burden", and therefore the carers" and family members' needs should not be forgotten. Many patients described the importance of their partner attending their medical appointments and being involved in the care pathway. Some patients reported "a total denial of the disease on the part of the family", with the result that the patient stopped communicating with the family about their condition "so as not to create discomfort and anxiety". Informing adult children of the diagnosis was also a major challenge.

The carers in the focus groups agreed that patient organisations were an essential source of support and information to them. This was considered especially important when the patient's family had been less involved in the patient's care pathway, wanted more information about the diagnosis and prognosis, or was struggling to accept the diagnosis. The carers described "how much they needed to encourage their

TABLE 3 A summary of actions proposed by the idiopathic pulmonary fibrosis (IPF) focus groups that could improve communications and, hence, IPF care

\section{Physician-patient communication \\ Specialist physicians should:}

Always use plain language, and be honest and empathetic

Allow adequate time for questions at the end of the appointment

Ensure there is a follow-up appointment (or telephone/e-mail contact) 1-4 weeks after diagnosis, when the patient has had time to digest their diagnosis and to formulate questions

Tailor information to the individual; the needs of each IPF patient will be different and will change over time

Explain all treatment options to a patient, even those that are not an option for them and explain why

Encourage patients to keep a health diary and to report any changes in their health at each appointment

Arrange a point of contact for the IPF patient, who can be contacted outside of scheduled appointments

Recommend that the specialist centre provide a list of reliable information sources that the IPF patient can go to for information

Provide clear guidance on medicines

Acknowledge and address any concerns with treatments that an IPF patient may be prescribed for comorbidities

Raise the issue of end-of-life planning with their IPF patient when it is a medical imperative or the patient requests information

Provide prompt access to a team trained in dealing with end-of-life issues

Explain the importance of remaining physically active to maintain health and for lung transplantation to the patient

Physician-physician communication

IPF physicians should:

Consider providing IPF patients with printed information (factsheet) that clearly outlines what IPF is and what treatment a patient is on, so that other HCPs can understand what the condition is

Ensure that the IPF patient's local doctor is kept up to date with all changes in the patient's care

Provide referrals for support services when they are needed le.g. psychological support, smoking cessation and nutritional advicel

Patient-patient communication

ILD specialist physicians and centres should routinely signpost patients and carers to local support groups to facilitate peer support

HCP: healthcare professional; ILD: interstitial lung disease. 


\section{TABLE 4 An overview of the common points covered in the idiopathic pulmonary fibrosis (IPF) charters}

\begin{tabular}{|c|c|c|c|c|}
\hline Theme & Europe & Ireland & UK & Canada \\
\hline Care & Equal access to care & $\begin{array}{l}\text { Access to appropriate } \\
\text { medicines and oxygen } \\
\text { therapy }\end{array}$ & $\begin{array}{l}\text { Access to seamless, } \\
\text { well-integrated health and } \\
\text { social care services, including } \\
\text { ambulatory and domiciliary } \\
\text { oxygen services personalised } \\
\text { to the needs of IPF patients }\end{array}$ & $\begin{array}{l}\text { Equal levels of care across } \\
\text { Canada based on the best } \\
\text { standard of care currently } \\
\text { available }\end{array}$ \\
\hline Information & $\begin{array}{l}\text { Comprehensive and } \\
\text { high-quality } \\
\text { information about } \\
\text { the condition }\end{array}$ & $\begin{array}{l}\text { Clear and concise } \\
\text { information about IPF in } \\
\text { plain language }\end{array}$ & $\begin{array}{l}\text { High-quality information about } \\
\text { the condition, including full } \\
\text { details of all treatment, } \\
\text { clinical trials, transplant, } \\
\text { support and service provision } \\
\text { options available to them }\end{array}$ & $\begin{array}{l}\text { High-quality and accurate } \\
\text { information about IPF, } \\
\text { including full details of all } \\
\text { treatments, clinical trials, } \\
\text { support, service provisions } \\
\text { and transplant options } \\
\text { available to them }\end{array}$ \\
\hline Support & & $\begin{array}{l}\text { Access to social, practical } \\
\text { and emotional support }\end{array}$ & $\begin{array}{l}\text { Access to dedicated peer } \\
\text { support networks, both for } \\
\text { patients and their carers, in } \\
\text { person or digitally }\end{array}$ & $\begin{array}{l}\text { Dedicated in-person or remote } \\
\text { peer support networks for } \\
\text { patients and their caregivers }\end{array}$ \\
\hline Palliative care & $\begin{array}{l}\text { Better access to } \\
\text { palliative care and } \\
\text { end-of-life care }\end{array}$ & & $\begin{array}{l}\text { Specialist palliative care and } \\
\text { end-of-life care; supported by } \\
\text { the Gold Standards Framework } \\
\text { where appropriate }\end{array}$ & $\begin{array}{l}\text { Improved, more accessible, } \\
\text { compassionate palliative and } \\
\text { end-of-life care when } \\
\text { appropriate }\end{array}$ \\
\hline
\end{tabular}

Bold text highlights where the point specifically relates to communication.

loved ones to attend the support group and their initial reluctance" but "they all felt that having attended, it was a very positive group and that in meeting others with similar problems and being able to help one another, both those with IPF and their carers felt less isolated".

A summary of actions proposed by the IPF focus groups that could improve communications and, hence, IPF care are provided in table 3.

\section{Discussion}

This paper highlights a range of issues raised by patients and carers that are centred on communication that when addressed, could improve the care and treatment of patients living with IPF.

Although not many studies have specifically focussed on communication issues in IPF, many of the points that have been identified in this paper have been reported previously, including: adequate time for consultation [2]; the importance of the IPF specialist in providing reliable and trustworthy sources of further patient information, and there being a key point of contact [2, 6-9]; concern of patients who want to understand how their stage of disease relates to its progression [8]; the desire for patients to have someone to discuss issues around medicines $[1,10]$; ensuring that local doctors are educated about IPF by 
the specialist and kept up to date with disease progression [11]; and increasing communication support as patients get less well $[12,13]$.

Other studies have identified the need for early discussions to improve the patient and carer experience of palliative care $[13,14]$. One study argued that as the goal of end-of-life planning is to optimise function, aid decision-making and improve quality of life, it should be introduced as a component of condition management [15]. A recent study looking into end-of-life care with IPF patients found that end-of-life decisions were still made very late. They concluded that early integrated palliative care with advance care planning could improve the end-of-life care of IPF patients [16]. Another study has shown that end-of-life discussion and planning as part of a multidisciplinary team can facilitate patients dying in their preferred location [17]. We acknowledge that it was difficult to discuss this issue if even one person in a group was uncomfortable with the conversation. Therefore, we can suppose that the opinions of the group may have varied.

Patients greatly value support services around their interaction with the general medical community. Other papers have also supported the view from our focus groups that wellbeing issues are important [2] and the key role that pulmonary rehabilitation can play, especially around transplantation $[11,18,19]$.

The psychological impact of IPF has been explored in other studies [20, 21]. Severe psychological distress is experienced at diagnosis, and when patients have to give up employment and hobbies, and sometimes also social activities, and risk becoming isolated.

The role of peer support came out very strongly in this study; perhaps this is to be expected, as the individuals who took part were already part of such a group and therefore may be expected to advocate for it. However, the role of support groups has been discussed positively in other studies as well [22].

It is clear that carers must not be excluded from communication involving IPF patients. Some $41 \%$ of the focus group participants were carers and so it is not surprising that the importance of carers was well covered $[2,7,23]$.

Many of the points on communication are common to other disorders, and have been highlighted in lymphangioleiomyomatosis [24] and lung cancer [25].

A number of IPF organisations have produced charters, outlining what is needed to improve the care of people living with IPF, including in Ireland [26], the UK [27], Canada [28] and one that has been developed for Europe [29, 30].

An overview of the points in each charter are given in table 4 and the points related to communication are highlighted in bold. These charters give a clear direction of where patients with IPF see the need for improvement and change. This paper reflects those points, and adds some more detail and context, and practical suggestions to make that happen.

Clearly, this paper reflects discussions held with a limited number of IPF patients from selected countries in Europe, which limits transfer of the outcomes to other geographical areas (e.g. Asia and Africa) where the needs may be different. Efforts were made to ensure that the opinions reported here are reflective of those individuals who took part in the groups, including providing systematic outlines for conducting the focus groups and guidance on report writing. Several topics were not highlighted or discussed by the focus groups (e.g. the role of healthcare systems) and this is a limiting factor to the way patient input was gathered.

\section{Conclusions}

Patients with IPF and their carers reported communication challenges in interactions with healthcare professionals, between healthcare professionals and from patient to patient, during four focus groups held in different countries in Europe.

Poor communication can lead to low confidence and anxiety about the quality of care and services IPF patients receive, and concerns about the management of medication and comorbidities. Effective communication is also vital to support psychological wellbeing.

Patients and carers look to their specialist ILD physician and centres to provide them with accessible information, medical support and signposting to groups and services to support and involve them throughout their care pathway.

Acknowledgements: This paper is in memory of Derek Ross. Derek, who had IPF, was an inspiring patient ambassador keen to use his experience with the condition to raise awareness of the issues facing people with IPF and to improve their care. Among Derek's key achievements in this field are speaking at the ERS International Congress and writing a chapter on key patient needs in the ERS Monograph on IPF [31], a prestigious publication for medical professionals. He also made significant contributions to an ERS Task Force on IPF treatment. 
We also greatly acknowledge the patients and carers from Belgium, Ireland, Italy and the UK who participated in the focus groups, shared their lived experiences of IPF and provided practical solutions to address their unmet health needs. We also thank the healthcare professionals who facilitated the group discussions and prepared the reports from the focus groups.

Conflict of interest: S. Masefield is a former employee of the European Lung Foundation. N. Cassidy reports grants from Boehringer Ingelheim Ltd, Roche Products Ireland and Three Lakes Partners to ILFA outside the submitted work. P. Powell is an employee of the European Lung Foundation. A. Wells reports personal fees for consultancy and speaking from Boehringer Ingelheim and Roche outside the submitted work.

\section{References}

1 Duck A, Pigram L, Errhalt P, et al. IPF care: a support program for patients with idiopathic pulmonary fibrosis treated with pirfenidone in Europe. Adv Ther 2015; 32: 87-107.

2 Russell A-M, Ripamonti E, Vancheri C. Qualitative European survey of patients with idiopathic pulmonary fibrosis: patients' perspectives of the disease and treatment. BMC Pulm Med 2016; 16: 10.

3 Cordier J-F. The expert patient: towards a novel definition. Eur Respir J 2014; 44: 853-857.

4 Hardavella G, Aamli-Gaagnat A, Frille A, et al. Top tips to deal with challenging situations: doctor-patient interactions. Breathe 2017; 13: 129-135.

5 Little P, Everitt H, Williamson I, et al. Observational study of effect of patient centredness and positive approach on outcomes of general practice consultations. BMJ 2001; 323: 908-911.

6 Wuyts WA, Peccatori FA, Russell A-M. Patient-centred management in idiopathic pulmonary fibrosis: similar themes in three communication models. Eur Respir Rev 2014; 23: 231-238.

7 Schoenheit G, Becattelli I, Cohen AH. Living with idiopathic pulmonary fibrosis: an in-depth qualitative survey of European patients. Chron Respir Dis 2011; 8: 225-231.

8 Sampson C, Hope-Gill B, Harrison N, et al. Care needs of patients with idiopathic pulmonary fibrosis and their carers. BMC Pulm Med 2015; 15: 155.

9 Mahler DA, Petrone RA, Krocker DB, et al. A perspective on web-based information for patients with chronic lung disease. Ann Am Thorac Soc 2015; 12: 961-965.

10 Costabel U, Bendstrup E, Cottin V, et al. Pirfenidone in idiopathic pulmonary fibrosis: expert panel discussion on the management of drug-related adverse events. Adv Ther 2014; 31:375-391.

11 Thickett DR, Kendall C, Spencer LG, et al. Improving care for patients with idiopathic pulmonary fibrosis (IPF) in the UK: a round table discussion. Thorax 2014; 69: 1136-1140.

12 Spagnolo P, Tonelli R, Cocconcelli E, et al. Idiopathic pulmonary fibrosis: diagnostic pitfalls and therapeutic challenges. Multidiscip Respir Med 2012; 7: 42.

13 Rajala K, Lehto JT, Saarinen M, et al. End-of-life care of patients with idiopathic pulmonary fibrosis. BMC Palliat Care 2016; 15: 85.

14 Swigris JJ, Stewart AL, Gould MK, et al. Patients' perspectives on how idiopathic pulmonary fibrosis affects the quality of their lives. Health Qual Life Outcomes 2005; 3: 61.

15 Ameer F, Crawford GB. Barriers to the provision of optimal palliative care in a patient awaiting lung transplantation. J Pulm Respir Med 2013; 3: 151.

16 Rajala K, Lehto JT, Saarinene M, et al. End-of-life care of patients with idiopathic pulmonary fibrosis. BMC Palliat Care 2016; 15: 85.

17 Kalluri M, Claveria F, Maged Haggag BS, et al. Early integrated palliative care in a multidisciplinary interstitial lung disease (ILD) collaborative reduces hospitalizations for idiopathic pulmonary fibrosis (IPF). Chest 2016; 150: $472 \mathrm{~A}$.

18 Adamali HI, Anwar MS, Russell AM, et al. Non-pharmacological treatment of idiopathic pulmonary fibrosis. Curr Respir Care Rep 2012; 1: 208-215.

19 Swigris JJ, Fairclough DL, Morrison M, et al. Benefits of pulmonary rehabilitation in idiopathic pulmonary fibrosis. Respir Care 2011; 56: 783-789.

20 Giot C, Maronati M, Becattelli I, et al. Idiopathic pulmonary fibrosis: an EU patient perspective survey. Curr Respir Med Rev 2013; 9: 112-119.

21 De Vries J, Kessels BLJ, Drent M. Quality of life of idiopathic pulmonary fibrosis patients. Eur Respir J 2001; 17: 954-961.

22 Olson AM, Brown KK, Swigris JJ. Understanding and optimizing health-related quality of life and physical functional capacity in idiopathic pulmonary fibrosis. Patient Relat Outcome Meas 2016; 7: 29-35.

23 Belkin A, Albright K, Swigris JJ. A qualitative study of informal caregivers' perspectives on the effects of idiopathic pulmonary fibrosis. BMJ Open Respir Res 2014; 3: e000007.

24 Bassi I, Hollis G, Cottin V, et al. Understanding the priorities for women diagnosed with lymphangioleiomyomatosis: a patient perspective. ERJ Open Res 2016; 2: 00102-2015.

25 European Lung Foundation. Patient Priorities for Lung Cancer Treatment and Care. www.europeanlung.org/ assets/files/Lung\%20cancer\%20patient\%20priorities/Patient\%20priorities\%20for\%20lung\%20cancer\%20treatment\% 20and\%20care.pdf. Date last accessed: May 19, 2017.

26 Irish Lung Fibrosis Association. National Patient Charter for Idiopathic Pulmonary Fibrosis. www.ilfa.ie/docs/ ILFA_CharterBooklet_lores.pdf. Date last accessed: May 19, 2017.

27 British Lung Foundation. Our IPF Charter. www.blf.org.uk/support-for-you/idiopathic-pulmonary-fibrosis-ipf/ project/our-ipf-charter. Date last accessed: May 19, 2017.

28 Canadian Pulmonary Fibrosis Foundation. CPFF Patient Charter. http://cpff.ca/get-involved/cpff-patient-charter/ Date last accessed: May 19, 2017.

29 IPF World. European IPF Charter. www.ipfcharter.org. Date last accessed: May 19, 2017.

30 Bonella F, Wijsenbeek M, Molina-Molina M, et al. European IPF Patient Charter: unmet needs and a call to action for healthcare policymaker. Eur Respir J 2015; 47: 597-606.

31 Ross D. Key patients' needs: a patient's perspective. In: Costabel U, Crestani B, Wells AU, eds. Idiopathic Pulmonary Fibrosis (ERS Monograph). Sheffield, European Respiratory Society, 2016; pp. 243-252. 